\title{
1. Systems of innovation for development in the knowledge era: an introduction
}

\author{
Helena Maria Martins Lastres, José E. \\ Cassiolato and Maria Lucia Maciel
}

\section{INTRODUCTION}

At the turn of the millennium, as radical transformations affect the ways we produce, reproduce and organize our very existence, the challenges to social and economic development seem, at times, overwhelming. What is the nature of these transformations? What are the interests and forces orienting them? What are the impacts of these transformations on the productive and innovative capacities of developing countries? How can they best face these challenges? What are the policy implications?

The aim of this book is to address these questions.

In what has come to be known as the 'Knowledge Era', the economy is relying on knowledge-based activities much more than ever before. There are at least three, interrelated, main arguments for this: (i) the proportion of labour that handles tangible goods has become smaller than the proportion engaged in the production, distribution and processing of knowledge; (ii) the share of codified knowledge and information in the value of many products and services is significantly increasing; (iii) knowledge-intensive activities are rapidly growing.

Obviously, information and knowledge have always been important in human history. But today's knowledge is more and more codified and the resulting information is more and more incorporated into goods and services. The development and diffusion of a new techno-economic paradigm, centred on information and communications technologies (ICT), have accelerated and deepened both the codification of knowledge and the spread of information. The extent, the velocity and the intensity of these changes have provoked, on one hand, an unbridled and uncritical enthusiasm with the multiple possibilities apparently available to all and, on the other, considerable perplexity as to how this transition actually affects 
social, economic and political processes and the best ways to deal with it. As we shall see, the nature of the transformations - and, therefore, of the challenges - is not always what it seems or is said to be. The first task, then, is to explore the reality behind the myths and to understand the real processes beyond the appearances and the rhetoric.

Part 1 discusses the main characteristics, threats and opportunities inherent to these transformations and resulting policy implications, taking particularly into account the new international environment shaped by the political context; process of economic liberalization; acceleration of the process of globalization and competition; emergence of the ICT paradigm and of the Knowledge Era. Different contributors here present new ways of looking at and interpreting the contemporary situation. Most chapters aim also at tackling the need to advance in the understanding of the specific challenges posed to developing and industrializing countries in order to design new types of policies, instruments and institutions adapted to their own requirements. Some take a more theoretical and general approach, others refer closely to specific experiences.

These efforts are particularly relevant due to the lack of an adequate framework to capture and deal with the new configurations. It is precisely this inadequacy that creates a fertile environment for the burgeoning of myths and contradictory interpretations. One of the main arguments of this book is that the specific features of the new pattern of development expose even more clearly the limitations of traditional approaches, theories and correlated indicators and statistical systems.

Moreover, our specific concern has been to develop new conceptual and methodological approaches to understand the particular difficulties and opportunities posed to developing countries and to design the guidelines for implementing the necessary strategies and policies. Part 2 of this book is aimed at filling this gap and explores the capacity of the systems of innovation approach to deal with this challenge. This analytical framework has the advantage of emphasizing historical, national and local trajectories and the systemic and interactive nature of innovation and learning (understood in a broad socioeconomic-political context with multiple sources and actors). This second part of the book comprises some of the main findings of our research project, set up with the objective of analysing experiences of selected local productive arrangements in Brazil in the 1990s. Factors affecting processes of learning, accumulation of productive capabilities, co-operative behaviour, innovation and diffusion strategies of firms and evolution of institutions were analysed.

The next section discusses some hidden aspects of current myths about information technologies and the knowledge era, pointing to those conclusions that are of particular interest for the issue of development. The third 
section examines the approach of systems of innovation, emphasizing the advantages of the concept for the analysis of developing countries. The fourth section introduces the concept of local productive arrangements and systems (and correlated methodology) developed and perfected through empirical research. The main objective here is to analyse how these arrangements were affected by the changes of the 1990s, through the examination of selected case studies in Brazil, presented in Part 2 of this book. The final section offers some concluding remarks summing up our arguments and suggestions toward the formulation of policies for developing countries.

\section{BEYOND THE MYTHS}

\section{Is Information a Synonym of Knowledge?}

In discussing the features of the new pattern of economic development, almost all authors represented here stress the need to distinguish information from knowledge. As put forward, for instance, by Johnson and Lundvall (Chapter 5), information refers to codified knowledge and is implied in the idea of 'know what'. Knowledge implies the elaboration of information and other inputs of all kinds to reach a new level, to 'know why'. This is why they propose a learning economy instead of a knowledge economy, arguing that their concept: stresses the process more than the product (that is, the stock of acquired knowledge) and, at the same time, underlines the importance of personal contact and interaction as the basic way to get access to new knowledge and technologies. ${ }^{1}$

The idea of a learning economy contrasts with other concepts stressing the role of information and ICT, its production and circulation; mainly because it refers to the social process of creation, acquisition, transformation, accumulation, diffusion, sharing (and also destruction) of specialized knowledge. It is in this sense that the emphasis is on the capacity to learn (as well as to forget) and to innovate as being crucial to the productivity and competitiveness of economic agents, rather than on the capacity to acquire and use new technical means.

In this book it is surely recognized that - with the spread of ICT, equipment and systems - information and codified knowledge can be more rapidly and easily produced and diffused throughout the world. However, it is also understood that non-codified knowledge remains tacit and is only transferred with interactive learning, through social, localized processes embedded in specific environments and organizations. Tacit knowledge is crucial not only to de-codify information and to make efficient use of these new technologies, but more importantly to generate new knowledge, which 
depends on local capabilities. Therefore, as Humbert (Chapter 6) puts it, the need to 'distinguish between [information and communication] technologies that can be imported and innovation capabilities that must be home grown as an outcome of the workings of a societal system' (p. 200).

Since 'knowledge society' or 'knowledge economy' can, in some formulations, imply that knowledge is already acquired and accessible to a society as a whole, the idea of learning society seems especially interesting for developing countries because it emphasises the process of learning and, therefore, of change. Further advancing this issue, Arocena and Sutz (Chapter 11) propose that the concept of 'learning societies' should refer to 'those societies where a fair proportion of the population and of the social and economic organizations permanently perform knowledge demanding activities, which are such that many actors need to, and are able to, upgrade their skills systematically' (p. 308).

\section{Is the Diffusion of ICT Leading to a New Sustainable Form of Economy?}

Elaborating on the issue of a knowledge (not information) economy, Freeman (Chapter 4) criticizes the myth that the diffusion of information technology would improve the perfectibility of markets. The main argument here is that the confusion between information and knowledge has also led to the misleading belief that the diffusion of ICT could provide more perfect information to all agents in various markets. It is also argued that information about price movements does not in itself convey understanding or predictability of market behaviour and trends. It is also noted that, far from reducing uncertainty, the fast diffusion of ICT and related innovations and transformations can actually increase it. And, as time goes by, his observations become even more prophetic:

There is nothing in modern ICT, which eliminates uncertainty in relation to investment behaviour, the most important source of instability in capitalist economies. The remarks of Keynes about expeditions to the South Pole remain as true today as when he first wrote them. Perhaps ... [these] expeditions have become less risky and have almost become routine. Not so, investments in Dot.Com companies. (p. 119)

In demystifying the idea that the diffusion of ICT could impart a longlasting high-growth trend to the United States economy and render it less vulnerable to cyclical phenomena, Freeman's conclusions in Chapter 4 converge with those of Chesnais and Sauviat (Chapter 3) and of Johnson and Lundvall (Chapter 5). While not underestimating the upward thrust from ICT and the special features that supposedly render the US economy more competitive and stable, most arguments here also include a critique of the 
ideological use of the term 'new economy' and the perspective that it points to a future of world stable prosperity led by the US. It is also emphasized that, although there are important justifications for the optimism in relation to changes associated to the diffusion of new technologies, there is less justification for underestimating the economic turmoil accompanying them.

Along this line, Freeman notes that the diagnosis and expectations that influential politicians, academics, bankers and industrialists in the US had about the economy in the 1920s are taken as a clear example of how the euphoria produced during a boom can distort the judgement even of those better informed participants and observers. He recalls his and Carlota Perez's argument that problems regarding structural unemployment and the slowing down of productivity result from the incompatibility between new technologies and subsisting social and organizational systems.

Of course, in this discussion it is important to take into account the alert made by Chesnais and Sauviat about opportunistic behaviour, which sometimes appears 'classified under the friendly and modern term institutional innovation' (Chapter 3, p. 89) and has fed ideological justifications for the reduction of the welfare state or for the flexibilization of work. This points to what authors like Santos (1994), insisted on, regarding the need to distinguish two different meanings of 'mode'. In periods of radical and pervasive transformations what is sometimes seen as characteristic of the new phase (mode) may be just a partial and biased interpretation (fashion) of what is still difficult to perceive and define. The 1990s witnessed some of these fashionable ideas, ranging from downsizing and reengineering to the Dow 36000.

Freeman's chapter - as most of the others, written in the first quarter of 2000 - discusses centrally the risks (and consequences) of a hard landing for the US economy, alerting that (i) euphoric ideas about the inauguration of 'new economies' are reborn in every big technological revolution; and that (ii) exaggerated expectations about the future of radical new technologies are just as inevitable as the collapse of those expectations. ${ }^{2}$

These alerts converge with other conclusions about the strong and weak points of the US productive and innovation system and of its sustainability in the long run. Johnson and Lundvall (Chapter 5) point mainly to the massive inflow and use of unskilled illegal workers and to the overestimated role of the hi-tech sectors. Chesnais and Sauviat (Chapter 3) reinforce these arguments, stressing that the myths about a 'new economy' tend to conceal the fact that innovation and development depend much more on the diffusion of knowledge than on information technologies.

Actually, different arguments in this book alert that, far from a real diffusion of knowledge, the 'new economy' reflects the reinforcement of the trend towards 'privatization', 'capitalization' and 'commoditization' of knowledge. 


\section{Knowledge or Ignorance Era?}

Chesnais and Sauviat (Chapter 3) draw attention to the need to reflect about the specificities and consequences of the advent and diffusion of the new pattern of economic accumulation taking into account its social, political - and ideological - context. They contrast the regime in place since the end of World War II with the present finance-dominated accumulation regime, in which:

- governments, in most countries, have accepted (or have been forced) to decrease their capacity to command the process of decisionmaking regarding investments, specially those with large structuring effects;

- adaptive strategies for $\mathrm{R} \& \mathrm{D}$, skill formation and investment (rather than innovative ones) prevail even in industries where $R \& D$ continue to be financed by large firms;

- most of the processes of restructuring, privatization, acquisitions and mergers have led to the dismantling of technological capacity.

The result is that stronger priority has been given to activities aiming at maximizing short-run returns on investment (such as 'downsizing') rather than those that have a longer payback period such as education and training of human resources and R\&D. ${ }^{3}$ Therefore, they point to the reduction of innovation-related investment and alert to the effects of this trend on the overall capacity of the system to produce knowledge and innovation in the future. Additionally, it is argued that this change is sustained, in the short run, by the exploitation of capabilities accumulated in the past, mainly through technological alliances and acquisition of capabilities in universities and public R\&D institutes.

These authors also make an important association between the financedominated accumulation regime and the development and diffusion of ICT, pointing out that the capacity of the productive system to cope with the new growth requirements is directly related to an extremely efficient use of these new technologies. They single out the unique position of the US within the new regime, and recalling the 'new economy' arguments, they maintain that these contribute to falsify its negative effects on innovation.

Discussing the increasing pressure towards privatization and 'commoditization' of knowledge, Johnson and Lundvall stress the inherent contradictions of this process and also alert that this may undermine some of the most important contemporary forms of creation and use of knowledge. 
Knowledge is socially produced in narrow and broad networks, which may be destroyed or at least damaged by a commoditization of knowledge. Growth in the learning economy feeds upon social capital. But if left to itself, it tends to undermine the very same social capital that it feeds upon. . . . the very rapidity of change may lead to a misallocation of resources in the sense that too little resources are used to pursue long-term objectives and the production of generic knowledge while too much is used to speed-up the movement along known trajectories. (Chapter 5, p. 148)

Freeman (Chapter 4) also calls attention to the trend towards 'capitalization' of knowledge - criticizing those who claim that this is the new mission of the 'modern university'. The main critique here is that what is mistaken by some as 'modern' (an institutional innovation associated to the new paradigm) is in fact the result of the pressures to privatize knowledge. He alerts to the risks of a decline in the quality of more fundamental research as well as in the quality of patents, recalling the new pressures to 'patent or perish', in addition to the older 'publish or perish'. In this case, we would emphasize the simultaneity and contradiction of these two pressures: to patent and publish; that is, that university activities tend to be pulled simultaneously in opposite directions.

This alert converges with one of the most interesting reflections made in this book: the consequences of pressures based on diametrically different concepts of knowledge - private and public; individual or collective. All over the world, these pressures are substantially altering traditional forms and infrastructure used to generate and diffuse knowledge. An implicit idea of several chapters in this volume is that in fact the present trends may be pointing more in the direction of an ignorance era, rather than a knowledge era. Important questions and alerts are made in Part 1 of this book concerning these trends. As all the authors are actually experiencing such transformations in our own work environment, we are among the first to enquire as to what are the expected consequences, and what should be the new role of universities and research centres.

Pointing out the pressures and risks of the development of an 'education industry', Petit explores the trends related to its linkages with ICT and the acceleration of globalization:

education, itself an industry, has tended to develop its international markets, attracting students from abroad with specific marketing and programmes and developing local subsidiaries and joint ventures. ICT are helping all these extensions. The potential of international development of these activities . . . seems noticeably important, all of which put the brain drain phenomenon in a new context. (Chapter 2, p. 52) 
Arocena and Sutz also manifest their concern about budgetary and ideological pressures forcing a more direct relationship between universities and the market, emphasizing that this problems is ever more serious in developing countries.

To be able to continue their research activities, universities and university researchers in Latin America must 'sell or die'. Moreover, the collaboration with enterprises tends to be seen by government and other sectors, particularly the mass media, as a must for universities if they have to be considered committed to the nation's fate. (Chapter 11, p. 300)

Along the same lines, Chesnais and Sauviat (Chapter 3) criticize the 'short-sighted apology of a market-dominated conception of higher education and research' - and warn that the pressures are not only financial. They are also ideological, under the recurrent slogan that 'everything the state did or still does the private sector, whether domestic or foreign, can do better'. In this sense, they point to the strength of the new 'theoretical' pressures to 'open and modernize' what they call the 'Republic of Knowledge'. ${ }^{4}$ They also make a more general alert that knowledge itself, in increasingly becoming a 'private property', has its role as an instrument of exclusion (as it replicates dominant geo-political and social structures) reinforced.

\section{Is There a Trend Towards Globalization or Exclusion?}

One of the most debated aspects of the recent changes occurring in the world is the acceleration of globalization of the economy and of knowledge. This process has been intensified by the expansion of new patterns of production, distribution and exchange based on the diffusion of ICT, allowing the interconnection of different and distant geographical parts of the world in real time and the communication and exchange of information in a way never experienced before. However, at the same time that we witness an amplification of the globalization process, a trend in the opposite direction is noticed. Together with the new possibilities offered by the increasing diffusion of ICT, new forms of social polarization and economic exclusion can be created. These are linked with unequal access to new products and services and opportunities to acquire and renew knowledge bases and skills, which are required to make use of them.

Instead of globalization, available evidence (i) shows that a significant concentration of trade, production and technology flows in more advanced countries - and particularly those belonging to the so-called Triad - persists; ${ }^{5}$ and (ii) suggests globalization (Humbert) and even re-concentration of knowledge and other strategic activities for firms and countries, related to planning and decision-making activities. Therefore, some few countries 
and firms act as the main generators of knowledge, new technologies and higher value added goods and services, with the vast majority being relegated to the role of passive users.

In this volume, and specifically regarding innovation and technology flows, Humbert (Chapter 6) also reinforces the conclusions that technology generation keeps being localized in specific parts of the world with no evidence regarding a de-concentration of these flows. In the Brazilian case, the author quotes analyses indicating the trend towards an exclusion of the country from global technology generation. Recalling the distinctions made above, it can be observed that the commoditization - and privatization - of knowledge tend to reinforce a concentration in the developed countries, which reproduces already existent geo-political patterns of inequality. In this sense, different authors in this book understand globalization as a more recent stage of an old historical process of internationalization of capital. Chesnais and Sauviat, for instance, argue in Chapter 3 that what is in fact observed is a movement of financial globalization, supported by ICT, and the search for an expansion of production and consumer markets, therefore the interest in expanding the reach of these new technologies and systems - especially the Internet - to all corners of the world.

Most authors in this volume agree that the advent and diffusion of the new ICT paradigm and accumulation regime have brought opportunities and threats to all countries, but particularly to those less developed. Chesnais and Sauviat are even less optimistic in their analysis of the impacts on the cohesion and the longevity of national and local systems of innovation in countries not belonging to the Triad nor possessing developed science and technology systems with a capacity for autonomous selfreproduction.

Arocena and Sutz also make explicit their preoccupation that inequalities between more and less developed countries may still increase. They stress that this widening of the gap refers not only to accessing and using new technologies (the 'digital divide') but, most important, to the capacity to learn, absorb and generate new knowledge and innovation (the 'learning divide'), as well as to the opportunity to use them.

We argue that this [focus on the digital divide] is a particularly misleading way of conceptualizing the actual problems of underdeveloped countries and of underdeveloped people. Of course, ICT and the Internet can be extremely useful tools in the many fronts of the fight against the flaws of poverty and isolation that accompany underdevelopment. However, putting the main emphasis on them is another example of the simplistic technological determinism that has so often inspired technocratic recommendations, historically incapable of redressing in a sustainable way the persistence of underdevelopment. We assert that the 
digital divide is an important but comparatively small component of the learning divide, where development divides are deeply rooted. (Chapter 11)

In the sense of contributing to minimize these negative effects of the globalization process, the importance is pointed out of centring the support to the diffusion of ICT on stimulating learning processes with the participation of local agents in networks, respecting the specific conditions of each country and region (Petit, Chapter 2; Humbert, Chapter 6). For developing countries, important issues refer to the existing workforce, its reduced levels of qualification and capabilities, and the brain drain. In a line similar to Arocena and Sutz's (Chapter 11) definition of the 'learning society', Petit (Chapter 2) warns that the 'rising inequality has been re-enforced by inequality in knowledge and education' and sees this process as a threat. Foray and Lundvall (1996) had also drawn attention to the risk of threatening social cohesion, if policies neglected the social and distributional dimension and the importance of promoting competences and learning capabilities as central elements in any strategy aiming at limiting the degree of social exclusion. They mainly warned of the risk of IT becoming an acronym for 'intellectual tribalism' instead of 'information technology'.

Reinforcing their arguments about the digital, learning and development divides, Arocena and Sutz emphasize the need to take into account both the opportunity to learn and the opportunity to apply creatively what has been learnt. In this sense they note that 'educational policies, even if fundamental, are not enough if people are not allowed to deploy its creativity, enhanced by formal training, into problem solving activities' (Chapter 11, p. 310).

Advancing further in the discussion of the consequences of the pressure towards privatization of knowledge, David and Foray (2002) recall that the appropriation of knowledge cannot be placed on an equal base with physical property, because knowledge and information are non-rival in use. They may be used repeatedly and concurrently by many people without being depleted. In fact, unlike energy and materials, information and knowledge are resources which are (more than abundant) inexhaustible. Their consumption does not destroy them; and when they are sold, transferred or given, this does not mean that they are lost. Despite this, they argue that individuals and firms today are striving to create artificial scarcities - by achieving legally sanctioned monopolies of the use of information - in fields where abundance naturally prevails, thus giving rise to an enormous amount of waste' (p. 14). However, even more important are the consequences in terms of further exclusion and development division. In a similar vein, we would argue that attempts to privatize and to create scarcity of knowledge are also associated with efforts to control and use it as 
an instrument of power. The implications of this process for the consolidation of a new form of geo-politics have to be taken into account.

\section{Have National and Local Policies Become Obsolete?}

The spread of simplistic ideas about globalization has also been accompanied by two main hypotheses. First, that in the 'new economy', economic and technological development was following a supposedly natural, progressive and unequivocal trend. Secondly, that local and national specificities would disappear and the role of policies (in general, and government policies in particular) would have no relevance. The arguments developed in this book converge regarding three main points in criticizing these hypotheses.

The first is that the agenda for policies - as put forward by most contributors to Part 1 - has become extended and even more complex rather than being made obsolete in the Knowledge Economy. Petit, for instance, refers to the need for 'more sophisticated and differentiated policy designing in accordance with the new context' (Chapter 2, p. 53). Pointing out that three main structural changes - the diffusion of ICTs, education and internationalization - are at the centre of the new contemporary policy issues, Petit explores their linkages and interdependencies. A number of other suggestions are given by different authors in this volume. The specific threats to and needs of the developing world, highlighting the arguments put forward in Part 1 (mainly by Coutinho, Chapter 12; Arocena and Sutz, Chapter 11; Diniz, Chapter 7; Schmitz, Chapter 10; and Mytelka and Farinelli, Chapter 9), as well as those by the Brazilian authors in Part 2 are discussed later.

Also, and as already seen, particularly in the case of promotion of ICT, the role of governments in the most advanced countries has been far from the passive non-interventionist stance rhetorically assumed. The fact that this has been especially true in the case of the US has contributed to place their socioeconomic institutions and policies as representing an international 'benchmark'; that is, a model that other countries should follow. However, this book argues that even if the US model were safe from risks, it certainly could not be reproduced and generalized. Specific and meaningful reference has been made to the case of venture capital in the US to illustrate that it is not transferable to economies that enjoy neither few or none of its peculiar privileges nor the particularities of its socio-economic institutions (Freeman, Chapter 4; Chesnais and Sauviat, Chapter 3; Johnson and Lundvall, Chapter 5).

These remarks take us to the second point of convergence: the recognition that national and local conditions may lead to completely different paths and to a growing diversity instead of the standardization and convergence suggested by the more radical theses about the influence of globalization on 
national and sub-national systems. As emphasized, for instance, by Celso Furtado,

globalisation is very far from conducting to the adoption of uniform policies. The mirage of a world behaving under the same rules dictated by a super IMF exists only in the imagination of some people. The disparities among economies are due not only to economic factors but, most importantly to diversity in cultural matrices and historical particularities. (1998: 74)

There is not only one solution and policy prescription, but rather a myriad of alternatives that could take different forms for different societies in different places and times.

The third point of convergence is on the understanding that the 'Knowledge Era' does not result from any neutral, natural or uncontrollable progressive force. Both the upsurge and diffusion of the new technoeconomic paradigm and the acceleration of the globalization process result from (and reflect) political and institutional changes which have characterized the environment of the most developed countries in the second half of the 20 th century. These changes have also oriented processes of deregulation, privatization and liberalization world-wide, supposedly associated with increasing needs of greater competitiveness, within an ideological framework that accepted no alternative.

As pointed out by Humbert 'the present neo-liberal promotion of globalization is a clear call for dismantling all barriers so that the nation-state territorial production apparatus of any country becomes open to any actors of the global system' (Chapter 6, p. 193). This author also recalls and discusses the slogan 'join the global train immediately or you're finished!' and the reactions it has provoked. ${ }^{6}$ Arocena and Sutz further develop this issue in Chapter 11, discussing the consequences for development of this hegemonic and globalized thought; exploring the challenges of avoiding both the integration' and 'apocalypse' visions; and pointing to the need to escape from this trap. They discuss the reasons why 'Southern frameworks of thought' developed in the 1950s and 1960s ('ECLA structuralism' and 'dependency theory') have not been replaced by a new holistic view, noting that

perhaps, as hegemonic thinking would claim, because there is no need for 'regional' frameworks of thought any more. Alternatively, it is possible to claim that they are indeed needed but that hegemonic thinking makes it very difficult to build them. (p. 293)

One of the main arguments of their chapter is that, despite the difficulties, a 'Southern framework of thought' is fundamental to the analysis of development problems related to knowledge, innovation and learning 
Also, contrary to the 'no alternative' thesis, some authors emphasize the need to understand the features of the present accumulation pattern and to design new policies and regulation regimes to orient growth and development. Along this line, Freeman points to the 'need for political regulation to limit or prevent undesirable social consequences of any new technology' (Chapter 4, p. 122). It is also in this direction that we understand the proposition - put forward in Part 1 of this book - of implementing a 'new new deal' (Johnson and Lundvall, Chapter 5) and of maintaining economic and social cohesion (Petit, Chapter 2). It is important in this discussion to reemphasize that policies targeting the learning issue are much more complicated when knowledge is seen as the main resource and learning the main process of economic development (Lundvall and Johnson, 1994) and cannot be taken in isolation from issues of economic, social and political power.

In a more general train of thought, Freeman notes that the reach and uncertainties associated with the diffusion of new technological systems justify why research on innovation systems is so difficult yet so important for policy-making: 'What is needed for this extremely difficult task of strategic policy-making is not just information but knowledge and understanding of the relevant system' (Chapter 4, p. 122). He and most authors in this book are concerned with investigating what new policies and policy tools would help in coping with the transformations discussed above, as well as be more adequate in stimulating industrial and innovative development. The development of the concept of national system of innovation in the mid-1980s represents an attempt towards this aim (Freeman, 1987; Lundvall, 1985).

\section{THE USEFULNESS OF THE CONCEPT OF A SYSTEM OF INNOVATION}

As pointed out in this book, underlying the system of innovation approach is:

- a resurgence of the interest in historical and national trajectories and in technical change;

- a characterization of innovation and learning in a broader context and as interactive processes with multiple sources;

- an emphasis on the importance of and complementarity between incremental and radical, technical and organizational innovations and their different internal and external sources;

- a re-conceptualization of the firm as an organization embedded within a broader socioeconomic-political environment reflecting historical and cultural trajectories; 
- a focus on the localized (and national) nature of the generation, assimilation and diffusion of innovation, as opposed to the simplistic idea of a supposed techno-globalism;

- an observance of the systemic nature of innovation and the importance of taking into account the productive, financial, social, institutional and political spheres, as well as micro, meso and macro dimensions;

- an emphasis on the importance of this concept for developing countries.

We will now highlight some of the main contributions of this book in the discussion of these features.

\section{A New Understanding of the Role and Characteristics of Innovation}

As particularly emphasized in Chapter 9 by Mytelka and Farinelli, the innovation system approach breaks ranks with the traditional view of innovation as a process of radical change at the frontier of an industry; and recognizes that innovation extends beyond formal research and development (R\&D).

Regarding the first point, and even while recognizing the central importance of ICT in the new accumulation pattern, most authors of this book consider that innovation, and hence development, are not confined to the new high-tech sectors. Mytelka and Farinelli provide conceptual and empirical support for this idea when they show how knowledge and innovation are radically transforming traditional industries. ${ }^{7}$ Analysing Danish and Italian agglomerations of small and medium enterprises (SMEs), they stress how these firms, collectively and as part of larger networks, are often very innovative, particularly regarding the development of new products. Saviotti also points out that 'the growing knowledge intensity of our economies demands a greater amount of search activities even for entry and for continued participation in traditional sectors' (Chapter 8, p. 235), implying that knowledge is indispensable in all economic activities, regardless of their being low- or high-tech. One consequence of this discussion is that the inadequacies of the traditional classification of economic sectors are becoming more and more evident. In fact, traditional vision based on sectors does not capture situations where the frontiers of industries are constantly changing and where market structures are becoming increasingly fluid. In a dynamic perspective, although technologies are highly influenced by sectoral technological paths, innovation is ever more influenced by knowledge and capabilities of different productive activities and scientific areas. 
The recognition that innovation extends beyond formal $\mathrm{R} \& \mathrm{D}$ activities, in its turn, emphasizes the importance of also taking into account continuous improvement in product design and quality; changes in organization and management routines; and creativity in marketing and modifications to production processes that reduce costs, increase efficiency and ensure environmental sustainability. Mytelka and Farinelli propose that innovation should then be understood as 'the process by which firms master and implement the design and production of goods and services that are new to them, irrespective of whether or not they are new to their competitors domestic or foreign' (Chapter 9, p. 250). This understanding, as they stress, helps to avoid an overemphasis on R\&D in the innovation process, encouraging policy-makers to take a broader perspective on the opportunities for learning and innovation in SME and in the so-called traditional industries. More than that and as we propose to explore later in this chapter, such a definition - that Mytelka has introduced in previous work - is particularly important for the analysis of innovation in less developed countries, and that is one of the reasons why the approach of a system of innovation and this broader concept of innovation is adopted in this book and orients the research agenda of RedeSist. ${ }^{8}$

It is worth pointing out that the recognition of these advantages does not impede us from appreciating the warnings given in Chapter 3 by Chesnais and Sauviat about the links between the global finance-dominated regime and this broader concept of innovation and innovation-related investments - which stresses mainly 'the marketing of new (or apparently new) products' - as well as the possible consequences to long-term education and R\&D investment, and particularly to the fundamental research base.

\section{Importance of Social, Political and Institutional Contexts}

As highlighted in Chapter 3 by Chesnais and Sauviat, the system of innovation approach emphasizes the importance of taking into consideration the historical, political and national trajectories. ${ }^{9}$ On the other hand, Mytelka and Farinelli (Chapter 9) note that this conceptual framework stresses the process in which enterprises - in interaction with each other and with other institutions - play a key role in bringing new products, new processes and new forms of organization into economic use. According to Freeman (Chapter 4), new forms of organization of production are related to new forms of social political organization. This is a slow process of reestablishment of an organic coherence, or compatibility - which is dynamic and not stable - between the mode of production and the social and political relations associated with it.

Since technological change is increasingly based on the production and 
diffusion of knowledge, development depends on the degree and the mode of accumulation and distribution of knowledge. Therefore, in the context of the new techno-economic paradigm, the generation and use of knowledge and the reduction of social inequalities become connected and reciprocally indispensable. The necessary strategies will depend on the capacity for technological and social innovation - in a country, a region, a community. This capacity is configured by social conditions existing in the cultural and institutional environment, more than by the availability of material resources. The immaterial changes, which occur in the production of intangibles as well as in material production, generate social change - hence the possibility of development. A country's (or region's) innovative capacity derives from the relations among its social actors, movements, organizations and institutions. And this capacity is its ability to make the most adequate choices, and to apply the results of those choices where they will be most productive, socially and economically. Historically defined cultural and institutional conditions are crucial in determining those choices. It is in this sense that the national system of innovation approach reinforces the thesis that the generation of innovation is localized and bound to national and regional frontiers, contrasting with the idea of a supposed technoglobalism. Since a significant portion of knowledge on which the innovation process is based is tacit, cumulative and localized, endogenous technological capabilities are required for the efficient absorption of knowledge, in order to adapt, modify and then generate, new knowledge.

The presumed globalization of the new techno-economic paradigm disguises the world-wide diversity of local and national solutions to economic problems. After all, 'the market' as a universal mechanism of co-ordination is an abstraction. To understand the possibilities of innovation, it is necessary to understand 'markets' (plural) as social structures built throughout history by social relations in specific institutional contexts. This is what is usually meant by 'embeddedness': the fact that all economic decisions and actions are embedded in the social context where they originate. It is significant that most of the authors in this book refer to the specificities of the social environments in which innovation occurs.

Thus the specific choices and characteristics of innovation in each country reveal complex and differentiated compositions of political-institutional arrangements, entrepreneurial cultures, social organizations, identities and citizenship construction. In fact, local culture is crucial in various processes of technical and related change due to the tacit and localized character of knowledge and the need to share language, trust and the feeling of belonging to the same community, allowing for interfirm communication and co-operation. This sense of identity and of common goals stimulates interaction and co-operation within a specific local culture of 
norms and values - in other words, social capital. ${ }^{10}$ In a similar vein, Humbert uses the expression 'societal capabilities for technical change or innovation' in Chapter 6 as a component of the innovation environment in his attempt to situate the process in its social context. The expression clearly translates the effort to understand the characteristics that are specific to a cultural and institutional environment where innovation does - or does not - occur.

Of the work presented in this book, the greatest emphasis on trying to define social capital is that of Johnson and Lundvall: 'social capital is a set of mostly informal institutions (social habits and norms), which affect the levels of trust, interacting and learning in a social system and cannot be accumulated in a straightforward way' (Chapter 5, p. 155). They suggest that social capital, together with learning processes, are the key to development strategies. Thus 'social capital' - the fabric on which the complex web of human creativity and innovative capacity can develop - is a complex set of norms, behaviour, values and tacit knowledge, historically and culturally constructed in each society.

This understanding is crucial to the analysis of innovation in developing countries, especially in Latin America, where certain cultural characteristics have often been considered as obstacles for development, such as personalistic and affective relations interfering in what 'should' be rationalistic and impersonal economic decisions. But values such as trust and loyalty are now repeatedly being considered as fundamental in the new paradigm and the relational society seems to be more attuned to the times, the spaces and the articulations of social and productive systems in transformation. In many cases, abilities - which have developed through history in order to cope with extraordinary difficulties - result in a capacity for flexibility and agile response to challenges, considered 'competitive advantages' in the contemporary economy.

The point here reinforces the argument that there is not one unique 'model' to be imperatively followed, and that no culture has a monopoly on the factors for successful socio-economic development. Each case must be studied according to its peculiarities, its specific characteristics, and the international context - with its limitations and opportunities - in order to evaluate what should be its own, specific, strategies and mode of development.

Guided by the lemma 'context matters', Arocena and Sutz discuss the differences concerning knowledge and innovation in the North and in the Latin American south. These authors stress the advantage of the concept of a national system of innovation as an analytical 'focusing device' for the 'centre' and also the 'periphery': 'Moreover, it helps to understand the knowledge and innovation distances between both realities; in fact, the 
concept itself shows differences when analysed from the South' (Chapter 11, p. 302).

\section{Financial Dimension}

Schumpeter (1912), in his Theory of Economic Development, recognized that for entrepreneurs to become the driving force in a process of innovation, they must be able to convince banks to provide the credit to finance innovation. In this sense, any discussion about innovation systems has to include the financial dimension. However, even if the conceptualization of systems of innovation has recognized the importance of finance, subsequent works have failed to include it in any significant way.

In Chapter 3, Chesnais and Sauviat point out the lack of concern for the conditions under which key participants in systems of innovation - firms, governments, and teaching, research and development institutions command the necessary finance allowing them to undertake long-term innovation-related investment. They propose that a foundation for a fruitful intellectual alliance should lie in recognizing the logic of the financedominated accumulation regime and its influence on innovation systems. As seen above, their main argument is that the present logic of the financedominated accumulation regime is responsible for the relatively low priority given by productive firms to long-run concerns, neglecting those activities that have a longer payback period, such as expenditure on human resources, $R \& D$ and innovation.

Taking into account this general picture of the world economy, one should reflect on the characteristics of financing and innovation that are specific to the developing world. Particularly stressed in this book is the fact that the financial dimension constitutes a very important factor for understanding the limits and possibilities of increasing competitiveness and innovative capabilities of local systems in the developing countries. Specific examples are given in Part 2, with the discussion of different productive arrangements in Brazil. In Part 1 this issue is also further discussed by Saviotti (Chapter 8), who exploits the limits of the institutional infrastructure for financing innovation in these countries. He suggests that institutional innovations involve two distinct lines of action. On the one hand, there are institutional mechanisms that guarantee the search for new niches or 'windows of opportunity' for generating innovations in the economy. On the other hand is the necessary existence of an institutional infrastructure to finance innovation.

Although this is a general problem, it is recognized to assume a larger dimension in the context of developing countries, where the inadequacy of both financial infrastructures and mechanisms for financing innovation 
(and in some cases even industrial development) is very often a marked characteristic. Most of these countries do not have 'functional financial structures', in the sense that private banks are not used to provide finance for long-term investment. ${ }^{11}$ Of course we believe that this inadequacy has to be understood in a broader context as that further discussed here mainly by Coutinho (Chapter 12); Arocena and Sutz (Chapter 11); and Chesnais and Sauviat (Chapter 3).

In Chapter 9, Mytelka and Farinelli advance in the direction of proposing both an institutional infrastructure and mechanisms for financing industrial development and innovation in less developed countries. Their basic idea is to target collective agents instead of individual firms. They propose the creation of cluster banks, embedded within local systems of innovation, aimed at fostering learning, specialization and innovation. The main argument here is that this would be particularly important in the restructuring and development of productive systems where SMEs are critical actors. ${ }^{12}$

The systemic approach provides a means of contextualizing these suggestions regarding the financial dimension of innovation systems in a broader context, which is at the same time specific and localized. It also offers a bridge between the micro-, meso- and macroeconomic spheres.

\section{Micro-Macro Relationship}

Analysing national and local systems of innovation, Freeman (Chapter 4) emphasizes the importance of taking into consideration its micro, meso and macro dimensions, as well as their linkages. He shows that the frailties of the so-called new economy - which are not usually discussed precisely due to the missing link between micro and macro on the analytical level point to the mistake of considering that an entire economic system can stand on a single set of technologies (in this case, ICT). By not considering the complexity of the entire array of social, economic and political structures which underlie them, calling for an equally complex and multidisciplinary treatment, the approach of mainstream economics cannot perceive the real sense - as meaning and as direction - of the new developments.

Similarly, Coutinho (Chapter 12) criticizes neo-classical theories, which reduce the macro dimension to a mere sum of the microeconomic short-run outcomes and adds that 'the specific characteristics of macroeconomic systems contain and condition the microeconomic decisions that form the standards of financing, corporate governance, international trade, competition and technical change' (p. 311). Making this issue the centre of his chapter, Coutinho discusses the influence of the micro-, meso- and macroeconomic dimensions and relationships on firms' behaviour, regarding 
especially their investment in productive and innovative capacities. Focusing on the Brazilian case, he discusses the specificities of the macroeconomic context of the 1990s (similar to other developing countries) resulting from the acceleration of financial globalization; as well as how this new context imposes even more serious limits on development policies.

The need to bridge the gap between micro and macro analyses finds a response in the systems of innovation approach and is especially relevant in the case of developing countries, given the peculiarities of their macro environments.

\section{Systems of Innovation and Developing Countries}

The systems of innovation approach has been criticized for the absence of formalization. However, it could be argued that the development of this approach did not intend to create a theory in itself but rather to provide a useful framework for analysing innovation dynamics. Additionally, it does not put innovation and learning processes into a strait-jacket model developed according to the specific experience of one (or a few) advanced countries, which could hardly be reproduced even in other economies in the North, not to mention the South. Therefore, what is seen by some as a disadvantage is here considered as the main element in providing a flexible and useful conceptual, methodological and analytical framework.

From the specific point of view of less developed countries (LDCs) the usefulness of this approach resides precisely in the fact that its central building blocks - diversity of social, economic and political agents and contexts; systemic approach, observance of micro, meso and macro relationships, etc. - allow for their specificities to be taken into account. Of particular relevance is the emphasis on the importance of innovation for the sustainable competitiveness of these countries and not traditional advantages such as low labour cost and natural resources, which Fajnzylber (1988) called 'spurious competitiveness'. Furthermore, understanding innovation as a localized, context-specific and socially determined process allows the demystifying of ideas about the possibilities of generating, acquiring and diffusing technologies in less developed countries. It makes clear, for instance, that acquisition of technology abroad is not a substitute for local efforts. On the contrary, one needs a lot of knowledge to be able to interpret information, select, buy (or copy), transform and internalize technology. Actually, it seems at least naïve to think that any firm would be willing to 'transfer' (or to share) precisely the main strategic competitive asset of the knowledge era. In this sense, ideas that technology is becoming a global commodity run totally against what is found today, with the pressures to privatize and control knowledge, as discussed above. 
Also important is the need to understand the specific conditions for financing innovation in less developed countries. All these and particularly the former, lead us to the relevance of linking micro, meso and macro dimensions of systems of innovation in the developing world. As pointed out by a number of Latin American and Caribbean authors, also of significant importance is to take into account the problems related to the instability and vulnerability of the macroeconomic, political, institutional and financial environments, which have been a marked characteristic of less developed countries. Additionally, some of them point to problems such as hyperinflation, high external debt and high interest rates as common important constraints to technological (and productive) development in these countries. ${ }^{13}$ One main argument here is that macroeconomic contexts in developing countries are of much greater importance than specific innovation policies. That is why they are called 'implicit' technology policies. ${ }^{14}$ And as Chesnais and Sauviat stress in Chapter 3, those contexts can be better understood if one takes into account the logic of the regulation regime, as in the case of the present (dominated by finance).

In Chapter 12, Coutinho goes further into the discussion of the specificities of the 1980s and 1990s contexts in countries like Brazil. He shows how, far from being neutral, interest rates and exchange rate policies - as well as their self-supporting interaction - impact directly on the core of the microeconomic business calculus, that is, on the essence of capital management. Coutinho also argues that economies that are subject to high rates of interest as a result of their macroeconomic systems place additional penalties on companies operating within them and emphasizes that if in addition to high levels of basic interest rates, the economy in question is classified as a country with high exchange rate risk ("Country Risk") its business sector is penalized even more heavily' (p. 312). His point is that, under a more globalized regime, the freedom to manoeuvre in determining interest rate/exchange rate policy depends even more on the foreign exchange position of the economies, both in terms of stocks (position as a creditor/debtor nation) as well as flows (surplus/deficit in the current account). As a consequence, to cope well with 'financial globalization' he recommends developing the means to avoid depending too much on it. His argument is that those countries with a more developed national innovation system will find themselves in a better position if they are in equilibrium or have a superavit in their balance of payments (as well as foreign exchange reserves), since they can grow faster with lower interest rates and reduced country risk-rate. In an opposite direction, countries with a less developed national innovation system will be in persistent disequilibrium in their current account, without a sustainable level of reserves, penalized by high risk-rates and needing to maintain high real interest rates. The result is 
macroeconomic vulnerability, which has been the case for most Latin American countries in the last two decades. He also notes that, paradoxically, developing countries that lack capital (and in theory should be running deficits in their current accounts, i.e. importing capital), tend to be punished by 'globalized finance' when they find themselves in a position of running persistent deficits. The opposite is true for countries that run surpluses, and which are able to enjoy both autonomy and favourable conditions - in terms of interest rate policy, and even having the option of placing selective controls on capital - although they could not enjoy the position of being net importers of capital, but would rather continue to base their economic performance on domestic savings.

Unlike the Bretton Woods system where the developing countries could incur modest external deficits (financed by direct investment or official loans) without imposing constraints on their interest rate policy, the current system of 'globalized financing' adversely affects the 'efficient allocation' of capital by punishing deficit countries and rewarding surplus countries.

As a consequence, Coutinho (Chapter 12) points out that, in the 1990s, the situation of the Brazilian (and Latin American) productive sector as a whole became particularly fragile because of the following macroeconomic aspects:

- weak competitive performance with outstanding trade fragility in all sectors of high added value and high technological content;

- widespread loss of national ownership in many sectors, weakness and reduced size of the remaining Brazilian business groups;

- persistent financial vulnerability of Brazilian-owned businesses resulting from very high costs of capital and inexistence of long-term financing mechanisms.

After further elaborating on these conclusions, his chapter concentrates on examining and proposing an alternative industrial policy for Brazil at the dawn of the 21 st century.

\section{LOCAL PRODUCTIVE SYSTEMS IN BRAZIL FACING THE GLOBALIZING LEARNING ECONOMY}

Part 2 of this book presents the results of the empirical research carried out in Brazil aiming at understanding local processes of learning and capability accumulation The systems of innovation framework was used in the analysis of 'local productive systems and arrangements'. Following this 
conceptual framework we define a local productive system as any productive agglomeration involving economic, political and social agents localized in the same area, performing related economic activities and presenting consistent articulation, interaction, co-operation and learning processes. It includes not only firms (producers of final goods and services, suppliers of inputs and equipment, service providers, etc.) and their different forms of representation and association, but also other public and private institutions and organizations specialized in educating and training human resources, $\mathrm{R} \& \mathrm{D}$, engineering, promotion, financing, etc. We have also developed the concept of local productive arrangements to include productive agglomerations, in which there is no (or almost no) articulation among the agents and which, therefore, could not be considered as systems. The development of this concept has been followed by a compatible empirical methodology 15 to gather information about the strengths and vulnerabilities of Brazilian productive, innovative and learning processes. This methodological framework covers micro, meso and macro elements influencing the evolution of the arrangements. Chapters 13 to 21 in Part 2 of this book comprise the analysis of ten selected case studies aiming mainly at:

- characterizing the local productive arrangements, main economic activities, products and services, firms, other public and private organizations, institutions and co-ordination structure;

- discussing the conditions under which local learning, the accumulation of productive and innovation capabilities and effective use of these capacities occur;

- determining in what sense the type of governance, competition pattern and market structure - local, national and international influence the evolution of the arrangement;

- investigating in what degree the competitiveness of the arrangement is sustainable and dynamic regarding embeddedness, articulation with the local system of innovation and main competitive elements (product quality, value-added, productivity and labour);

- examining the influence of the 1990s and of local and national, explicit and implicit policies on the evolution of the arrangements.

The resulting policy implications are summarized by Cassiolato, Villaschi Filho and Campos in Chapter 23.

The map in Figure 1.1 locates these ten empirical studies, selected from the 26 productive arrangements analysed in Brazil and Uruguay, from 1998 to 2000 and Table 1.1 presents a summary of these cases. The first column of the table comprises five cases of arrangements of SMEs without any 


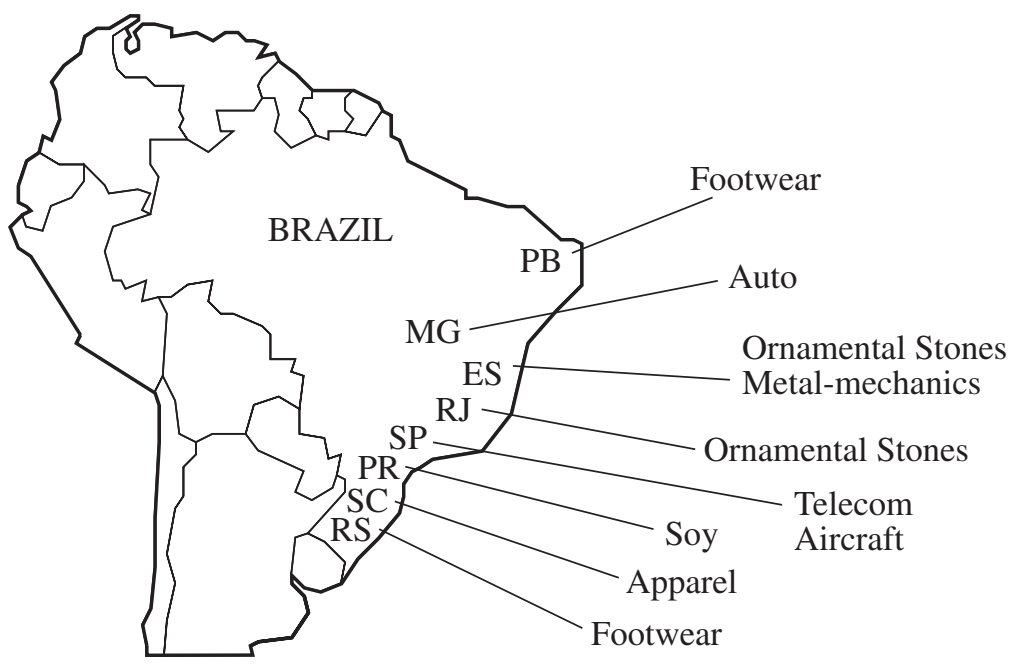

Figure 1.1 Map showing local productive arrangements in Brazil

local co-ordination by large firms. They produce mostly commodities. Two are mainly geared to the external market (ornamental stones in Espírito Santo and footwear in Rio Grande do Sul), others to the internal market (footwear in Paraíba and ornamental stones in Rio de Janeiro), while the arrangements for apparel target both external and internal markets.

The second column comprises three cases of arrangements dominated by large firms. One is controlled by a local subsidiary of a TNC, the Italian auto-maker Fiat. Another is dominated by a recently privatized locally controlled large firm, the aircraft producer Embraer. The third is an arrangement of local SMEs in the metallurgy-mechanics sector selling to large firms, both locally owned and TNC subsidiaries. Although all these large firms export, Fiat concentrates on the internal market, while the other two cases could be considered export-intensive.

The third column consists of productive arrangements anchored by a public entity, such as universities and research centres: telecom in São Paulo state and soybean in Paraná. Both include locally owned SMEs and large subsidiaries of TNCs.

\section{SME Arrangements}

Lemos and Palhano (Chapter 13) analyse the leather footwear arrangement in Paraíba state, located in the poor northeast region of Brazil. The main interest lies in its characteristics of production of traditional goods of low 
Table 1.1 Surveyed local productive arrangements in Brazil-2000

\begin{tabular}{lll}
\hline SME arrangements & \multicolumn{1}{c}{$\begin{array}{c}\text { Arrangements } \\
\text { controlled by large } \\
\text { firms }\end{array}$} & $\begin{array}{c}\text { Arrangements organized } \\
\text { around government } \\
\text { institutions }\end{array}$ \\
\hline $\begin{array}{l}\text { Footwear (RS and PB) } \\
\text { Apparel (SC) }\end{array}$ & $\begin{array}{l}\text { Aircraft (SP) } \\
\text { Ornamental stones (RJ and ES) }\end{array}$ & $\begin{array}{l}\text { Telecom (SP) } \\
\text { Metal-mechanics (ES) }\end{array}$ \\
\hline
\end{tabular}

technological complexity, involving a significant number of formal and informal micro and small firms. Local production targets a wide regional low-income market. The authors found important interactions and links among firms and between them and other institutions. These relate to learning processes and to enhancing technical capability in this backward productive environment. They also emphasize the negative impact of policies pursued during the 1990s on these interactions and learning processes. Particularly worth mentioning is that the incentives for relocation of large footwear firms from the south of the country to the northeast only resulted in assemblage operations being located in the area, with no significant links or impact on local capabilities.

A totally different case in the same sector is analysed by Vargas and Alievi (Chapter 14). They investigate innovative and competitive trajectories in the leather footwear arrangement in Sinos Valley in Rio Grande do Sul state in the far south of Brazil. This is perhaps one of the most studied arrangements in the developing world, being a classical example of SMEs participating in a global commodity chain (see Schmitz, Chapter 10). The focus of the chapter is on the nature and intensity of co-operative linkages and interactive learning mechanisms among actors within the arrangement. It emphasizes the diverse upgrading strategies associated with different market channels. On the one hand, a considerable number of firms remain integrated in global commodity chains and maintain innovative capabilities only in the sphere of production. On the other hand, some firms have upgraded their innovative capabilities, entering into design and marketing. During the 1990s, this latter group of firms managed to raise exports to new market niches, but they are still an exception. The authors discuss why and how co-operative behaviour significantly decreased in both cases in the 1990s as compared with the previous decade.

Campos, Cário and Nicolau (Chapter 15) analyse the textile and clothing productive arrangement in the Itajai Valley in Santa Catarina state. Spread throughout 32 towns, the arrangement is characterized by comprising the most significant segments of the Brazilian textile and clothing 
chain, including threading, weaving, dyeing and the manufacturing of apparel. There are important local institutions, such as education, training and research centres, consultancy and other service providers, producers' associations and workers' unions. However, co-operative learning happens only 'horizontally' (among firms producing similar goods) with no 'vertical' relations and very little interaction between firms and other institutions. The authors suggest that the local institutional base for innovation is 'non-structured and passive', even though they recognize conditions for a structured, active and co-operative innovation system.

Villaschi Filho, Pinto and Sabadini (Chapter 16) deal with different trajectories in the exploitation of ornamental stones in two neighbouring areas. One is located in Rio de Janeiro state; the other, in Espirito Santo state, is the country's largest exporter of marble and granite. Both specialize in low value-added goods and share a low concern with environmentally safe production processes. The authors describe the local arrangements, examining why spatial proximity in both cases has not been a sufficient enabling factor in stimulating learning and co-operative processes. Innovationrelated learning is absent in both arrangements, but not because of a lack of capabilities and knowledge at the local level. There are organizations, both private and public, that can stimulate these activities and contribute to creating dynamic capabilities. The authors also suggest the existence of a vicious circle with short-sighted trade policies ('export at any cost') leading to the exploitation of natural resources with low value-added and a lack of concern with respect to local capabilities which could lead to an increase in local content.

\section{Arrangements Controlled by Large Firms}

Lemos, Diniz, Santos, Crocco and Camargo (Chapter 18) analyse the automobile arrangement in Minas Gerais state. It is characterized as a hub and spoke, with local governance based on a subsidiary of a TNC in which the domestic market is strategic for the company's competitive position. With liberalization a rapid internationalization occurred: Italian firms acquired all but one of Fiat's first-tier suppliers. These changes led to a sharp decline in $R \& D$ and other innovative efforts at the local level. Already existing suppliers and new entrants started locating their innovative activities and decision-making centres in their headquarters in developed countries, basically Italy. As a result, co-operative arrangements between Fiat and its suppliers changed, as the requirements regarding the development of technological capabilities became less important than the enhancement of technical and managerial efficiency associated with particular processes.

Bernardes and Oliveira (Chapter 20) analyse the evolution of the São 
Paulo aerospace productive arrangement. They investigate the innovation regime, learning processes and technological relations among firms, and local research and training institutions after the privatization of Embraer in the mid-1990s. Embraer, the fourth largest aircraft producer in the world, became in 1999 the largest Brazilian exporter, with US\$ 1.8 billion in international sales. Their main findings point out that the lack of an efficient and co-ordinated national policy for the sector has caused a paradoxical movement impelled by the rapid globalization of Embraer's commercial, productive and technological activities. Although there was an improvement in the management of the global production chain governed by Embraer, mixed results in the development of innovation capabilities were found. These include a concentration of innovation activities in the global productive network, and the weakening of the Brazilian innovation system as the national supply base decreased.

Villaschi Filho and Lima (Chapter 21) deal with the interaction between an SME local arrangement specialized in metal-mechanics and large commodity exporters - mainly steel, paper pulp and iron-ore/iron-ore pellets in Espírito Santo state. These interactions have taken place through buying orders placed by these anchor firms with local producers and through the setting up of several programmes aimed at increasing their industrial capabilities. Despite the good results that were achieved in the 1990s, their chapter draws attention to the need to foster new types of co-operation between the anchor enterprises and the SMEs of the system.

\section{Arrangements Organized around Government Institutions}

Paula, Porcile and Scatolin (Chapter 17) analyse the innovative institutional arrangement organized around the development of new varieties of soybean in the state of Paraná. From the 1970s, this arrangement experienced considerable dynamism, largely due to the key role played by the local branch of Embrapa (Brazilian Enterprise for Agricultural Research, a government-owned agricultural research institute). The authors stress that Brazil is now a key player in the international soybean market thanks to this local innovation system centred around Embrapa. The study differentiates between two parts of the arrangement as far as technological and market dynamism is concerned: one producing new cultivars and seeds; and the other producing grains and crushing. It shows that only in the first case do interactions between heterogeneous actors and different types of technology create synergy, with a positive impact on the evolution of productivity and competitiveness. The authors also discuss the consequences of the new Law of Varieties (approved in April 1997) which introduced royalty payments for new cultivars. Although the new configuration of the 
industry was still in a transitional period, some trends were noticed. These include a concentration of the market structure through the entry of large firms and the elimination of small firms, a higher rate of introduction of new cultivars and the dismantling of co-operative mechanisms for testing and assessing new cultivars. Exploring the policy implications of their discussion, the authors point to the need to avoid excessive market concentration and to foster the interactive learning process.

Szapiro (Chapter 19) analyses the telecom arrangement in the state of São Paulo. During the 1970s and 1980s Brazil developed an innovative and productive system of telecommunications in Campinas, constituted by CPqD (the R\&D Centre of Telebrás ${ }^{16}$ ), the State University of Campinas, multinational subsidiaries and nationally owned equipment producers, operators and other research institutions. Szapiro analyses the impacts of structural reforms (liberalization, deregulation and privatization) on this system in the 1990s, pointing out that besides its restructuring, new firms were set up but several either disappeared or were acquired by foreign firms. The author also (i) notes a decrease in the degree of collaboration between carriers, equipment producers, research centres and regulatory bodies and (ii) concludes that the processes of trade liberalization, privatization and deregulation have led to the disarticulation of the local innovation system and to the destruction of intangible assets of firms and institutions, deeply affecting their core competences.

\section{Synthesis of the Performance of Brazilian Productive Arrangements in the 1990s}

There were some common features regarding how these selected Brazilian arrangements coped with the transformations of the 1990s. In general most firms' competitive strategies concentrated on improving production organization, product quality and modernization of production processes, normally through equipment imports. On the one hand, there was an increase in the learning capacity of firms, with emphasis on organizational efficiency, skills and production organization. Most arrangements centred their efforts on improving production processes, while only a few also focused on developing new products.

On the other hand, reforms had also a negative impact on learning capabilities. Collaborative efforts, in most of the cases studied, did not increase in the 1990s, quite the opposite. In fact, the empirical results show that in arrangements dominated by subsidiaries of TNCs, technological collaboration significantly decreased during the period. Even in the cases where collaboration increased - basically in arrangements controlled by local firms that target their production to the internal market - a very slow 
increase in formal co-operation with local institutions and firms was detected. The survey also confirmed that when co-operative relationships occurred, they were mostly based on transfer of tacit knowledge and implied a high level of informality. It was not the result of any deliberate strategy.

Although the export profile of the Brazilian economy has evolved in such a way that industrialized goods are increasingly important, their insertion in the international market is still characterized by exports of commodities that are intensive in natural resources and/or energy and generate low wages. These commodities have shown a tendency for low dynamism, excess supply and price stagnation.

To sum up, the main conclusions of the research project on local productive and innovative systems in Brazil have provided evidence that, in the 1990s, with few exceptions, instead of being reinforced:

- productive and innovative efforts were decreasing;

- productive and innovative networks were disarticulated (with no significant articulation between the new investments and local agents);

- the level of employment of specialized personnel decreased.

Arocena and Sutz (Chapter 11) also discuss a number of similar examples observed in Latin America of this process that they call 'de-learning', emphasizing the consequences of weakening the socio-technical capabilities accumulated over a long time without replacing them.

Katz (2000), in his analysis of the impact of structural reforms on the Latin American economy, also suggests that, although the process of structural reforms of the 1990s was successful in restoring macroeconomic equilibrium in most countries of the region it did not bring any significant improvement in terms of productive efficiency and distributive equity. His findings also coincide with ours in that most of the productivity gains were obtained by traditional sectors. At the same time, knowledge intensive sectors lost ground. More than that, the productive gains observed in traditional sectors were associated with both employment reduction and diminishing importance of local content, affecting mostly local SMEs.

However, the discussion in Part 2 of this volume also shows that, despite the difficulties, all the surveyed arrangements have survived. Firms face a very uncertain future but were capable of restructuring and adapting to the new environment. Some are even moving towards more complex production systems. This also happens to local institutions, including those in charge of fostering co-operation among actors and promoting learning and capacity building. A particular feature of the Brazilian productive arrangements continues to be their institutional density. In this sense the analysis 
of the case studies showed that the arrangements retain the basic conditions on which virtuous processes could be built.

The empirical chapters provide very rich and detailed information about strengths and weaknesses of the arrangements as well as policy recommendations. The analysis reinforces the idea that it is not only the importance of local aspects that matters, providing evidence that there are important elements of the national and international dimensions that obstruct or favour their evolution. In every sense, the conclusions of the empirical studies are the result of the policies adopted in Brazil in this period - inspired by the structural reforms model - which have contributed to conform to a 'malign macroeconomic regime', as characterized by Coutinho (Chapter 12). Instead of fostering local capabilities, the 'competitive insertion' model, adopted in Brazil and other Latin American countries, assumed that:

- the opening of the economies and the attraction of foreign investment would be the best way to improve the manner and the degree of integration of these economies in the world market;

- technology, innovation and knowledge could be globalized; and like a commodity, could be acquired internationally under market conditions. $^{17}$

The economic results obtained in the period question the appropriateness and effectiveness of the policies adopted regarding their very basic target: increase of competitiveness and a positive insertion in the globalization process. $^{18}$

\section{CONCLUSION}

Three interrelated points mobilize the discussion on the need for new forms of policies to foster productive arrangements in developing countries. One refers to the challenge of transforming existing arrangements into dynamic and innovative systems. That is, how to foster and support an agglomeration of firms and other institutions in their process of becoming an articulated group of agents that can collaborate in production, innovation, design, marketing, commercialization, and so on. The second point relates to the need to create conditions to allow the emergence of new productive arrangements and systems. In this case the challenge is also to give them conditions to grow and sustain their growth.

Some of the authors advance into the discussion of policy implications and also deal with a challenge, whose importance was emphasized by 
Schmitz (Chapter 10) and Diniz (Chapter 7) - the need to articulate policies and institutions of different scope. This refers to two lines of ideas. The first is that there is no single (and common) magic formula to be applied in all cases. The second refers to the need to articulate different levels (from the local to the national and international) and kinds of policies as well as intervening institutions. As noted by Diniz:

this task requires a permanent effort, which depends on the creation or strengthening of local coordinating agencies, such as local development agencies, labour unions, entrepreneurial associations, or other forms of local coordination. As each locality or region has its own characteristics, it is not possible to suggest or implement uniform structures. (p. 223)

Thirdly and more importantly, there is a need to establish adequate macroeconomic conditions, not only to allow these two other targets to be fulfilled, but also to reverse the situation of destruction of existing local productive and innovative capacities that had been previously accumulated, as documented in this book.

Of course it is acknowledged that there is much 'destruction' occurring all over the world, not only in Brazil and other developing countries. However, the serious economic and social situation confronting LDCs almost without exception calls for an urgent start of a concerted and continuous phase of 'creation' instead of destruction. Creating and sustaining opportunities for learning and innovating should be at the centre of the new public and private strategies and policies targeting the promotion of the capacity to acquire and use knowledge.

We have argued that one of the main problems facing Brazil and other Latin American countries, and which endures at the beginning of the millennium, results from at least a very poor understanding of the nature and consequences of the transformations, as well as their impacts on these countries. Policies adopted in most of Latin America reflect these misunderstandings. ${ }^{19}$ This is particularly true and worrisome because we are living in a phase of radical transformations, when new patterns of development are being shaped.

Defining and implementing effective policies to cope with such a complex situation are not easy tasks. More importantly, as argued in Part 1 and documented in Part 2 of this volume, general conditions for implementing policies significantly deteriorated in the 1990s. However, another argument here is that one main reason for the crisis of adaptation to the new patterns refers precisely to the delay in designing appropriate policies and instruments to cope with them. Hence the need to advance towards an adequate understanding of the characteristics and impacts of the new pattern of accumulation and to design and implement policies, taking into account 
local, national and international conditions for development as well as the changes associated with new forms of governance at world level.

We believe that the discussion offered by the different authors in this book represents an important contribution in this direction. We also hope to stimulate developing countries to formulate their own intellectual frameworks; to adopt analytical approaches capable of dealing with their new challenges and opportunities; to find their own paths and rhythms of development; and to define and implement the most adequate related policies.

\section{NOTES}

1. 'Simply defined, a learning economy is an economy where the ability to learn is crucial for the economic success of individuals, firms, regions and national economies. Learning refers to building new competencies and establishing new skills and not just getting access to information' (Johnson and Lundvall, Chapter 5, p. 143).

2. Two years after the conclusion of the first versions of these papers, more than US\$ 7 trillion were written off from the US stock market, many 'dot.com' firms have collapsed and a series of frauds of firms such as Enron and WorldCom have confirmed their predictions and concerns.

3. Chesnais and Sauviat note that there are, however, important exceptions to this pattern in countries where (i) the government remains as the focal point in the national system of innovation; (ii) the process of privatization faces internal political opposition and (iii) the need for a continuous public support for science and technology is still recognized (see Chapter 3).

4. 'These institutions - universities, but also scientific academies, learned societies and networks of exchanges of people and ideas- ruled the attitudes and codes of behaviour for the disclosure, the critical inspection and discussion, and the circulation and availability of new knowledge. Over the last 20 years these codes of behaviour (the "ethics" of scientific research) and in particular the norm of rapid and total disclosure have been subjected to ever increasing pressure' (Chesnais and Sauviat, Chapter 3, p. 88).

5. See Freeman (1991); Lastres (1993) and (1997).

6. About these issues see also Fiori (1995); Tavares and Fiori (1997); Furtado (1998).

7. Among others Smith (1999) also pointed out that the fishing sector, normally characterized as low-tech, could be characterized nowadays as knowledge intensive (and even high-tech), for the increasing use of new materials and design concepts in ships, fishing equipment and pond technologies; computer imaging and pattern recognition technologies, satellite communications, global positioning systems, safety systems, sonar technologies, optical technologies for monitoring and sorting fish; nutrition technologies based on biotechnology and genetic research, etc.

8. For details see www.ie.ufrj.br/redesist.

9. As for instance noted by Chesnais and Sauviat, 'Following the dismantling of industrial and technological development policy instruments as well as of trade protection, there is a sudden realization that history, in the form of national trajectories shaping social behaviour, matters. . . . This renewed importance of historical trajectories is of course one of the clues to understanding why, paradoxically, interest in national systems of innovation grew alongside the onset of globalization' (p. 82).

10. For more details see Albagli and Maciel (2002) and Maciel (2002).

11. See, for instance, Studart (1995), Melo (1996), Cassiolato and Lastres (2000).

12. For more details about the development of these ideas in the Brazilian case, see Mytelka (2001) and also Vargas, Cassiolato and Britto (2001). 
13. See, among others, Villaschi (1993); Melo (1996); Girvan (1996); Viotti (1997); Sutz (1999); Katz (1999); Arocena and Sutz (2000a).

14. See Cassiolato (1992) and Sagasti (1978).

15. For details of this methodology, including the three types of questionnaires developed to base the field-work, see www.ie.ufrj.br/redesist. The results of the work developed by the research network established in 1997 are also available there.

16. Telebrás was the government holding of the telecom system in Brazil until its privatization in the mid-1990s.

17. For details see Lastres and Cassiolato (2000).

18. Attempts to accelerate the integration by attracting foreign capital resulted in an effective increase of foreign direct investment (FDI). The flows of foreign investment increased from US\$ 8 billion in 1990 to US\$ 67.3 billion in 1998, and the stock of FDI grew 60 per cent in the period (Mortimore, 1999). Although inflows in the 1990s were approximately 13 times those observed during the 1970s, economic growth was 50 per cent lower. It is worth noting that FDI in the 1990s was mostly directed to mergers and acquisitions of existing firms rather than 'greenfield' investment. Also, and contrary to what was planned, these new investments were basically import-intensive and not geared to exports, targeting mostly local markets. An additional great concern relates to the sustainability of this situation.

19. Lastres and Cassiolato (2000); Cassiolato, Lastres and Maciel (2002). 
Helen Maria Martins Lastres, Jose E. Cassiolato, and Maria Lucia Maciel - 9781781009895 Downloaded from PubFactory at 04/26/2023 11:07:39AM 


\section{PART I}

Systems of Innovation for Development in the Knowledge Era 
Helen Maria Martins Lastres, Jose E. Cassiolato, and Maria Lucia Maciel - 9781781009895 Downloaded from PubFactory at 04/26/2023 11:07:39AM 